\title{
Nota sobre esta edición
}

La presente edición de Cuadernos de Antropología trae cuatro artículos elaborados desde la Historia de la Antropología, Antropología Urbana, Antropología del Cuerpo y Etnoarqueología. En esta ocasión nos sentimos complacidos de que los aportes vengan de profesionales dedicados no solamente dedicados a la Antropologìa, si no también desde la Historia, lo que en definitiva enriquece los puntos de vista de nuestra disciplina.

El primer documento El otro en la mirada etnográfica. Guatemala (1920-1950), analiza diferentes representaciones de comunidades indígenas guatemaltecas durante la primera mitad del siglo XX, así como las perspectivas desde las cuales etnógrafos y antropólogos alemanes y estadounidenses explicaron las características culturas de estos pueblos.

La autora, Patricia Alvarenga, realizó sus estudios de grado y de maestría en Historia en la Universidad de Costa Rica, es Ph.D. en Historia por la Universidad de Wisconsin, Madison, E.E.U.U. Estudiosa de las relaciones interétnicas, los movimientos sociales, el género y la sexualidad. Es catedrática de la Universidad Nacional y se desempeña como académica en la Escuela de Historia de dicha universidad y como investigadora del Centro de Investigación en Identidad y Culturas Latinoamericanas (CIICLA). Ha indagado en la construcción del poder desde la óptica de la participación del mundo subalterno tanto en la resistencia como en la colaboración.

Jim Weyl y Anayensy Herrera colaboran con La herencia alfarera en la península de Nicoya: Persistencia de una tradición, donde los autores documentan la manufactura de tres tipos de piezas cerámicas en San Vicente de Nicoya, lo que, como indican ellos, posibilita inferencias en cuanto a las continuidades y los cambios en las materias primas, las herramientas, las técnicas, la organización del trabajo, los estilos y los usos.

Cuadernos de Antropología 2014, 24(2), 1-2

Revista del Laboratorio de Etnología María Eugenia Bozzoli Vargas Escuela de Antropología, Universidad de Costa Rica http://revistas.ucr.ac.cr/index.php/antropologia ISSN 2215-356X

cC) (i) (-) Cuadernos de Antropología está bajo una licencia Creative Commons Attribution-NonCommercial-ShareAlike 3.0 
En cuanto a los autores, Jim Weyl es antropólogo social con doctorado de Columbia University en Nueva York. Tiene veinte años de investigaciones y colaboraciones en la comunidad artesanal San Vicente de Nicoya. Es especialista en la antropología de trabajo enfocado en los cambios en la manera de ganarse la vida en Costa Rica frente al crecimiento del turismo. Ha sido profesor del programa Fulbright en la Escuela de Antropología de la UCR y profesor en el Instituto Monteverde.

Anayensy Herrera es arqueóloga licenciada de la UCR. Más de veinticinco años de experiencia en investigación arqueológica, diseño y ejecución de proyectos con diversas entidades como el Museo Nacional, el Instituto Costarricense de Electricidad y Asesorías Arqueológicas LASA. Estudios diversos en los que se incluye los estudios comparativos, la experimentación científica y la investigación etnográfica, aplicados a los campos de la producción, tecnología y estilos de la alfarera precolombina y moderna, técnicas de extracción, procesamiento y producción de alimentos, adornos y herramientas sobre conchas de moluscos, rocas y huesos.

Regulación, representación y experiencia del cuerpo deportivo femenino: Tres formas de ver a las mujeres en el ring, es un interesante documeto que realiza un recorrido por la Antropología del Cuerpo, abordando la incursión de las mujeres en deportes tradicionalmente "masculinos", como el boxeo. Escrito por Catalina Delgado, politóloga con énfasis Arte y Literatura de la Universidad de los Andes, Colombia, y Magíster en Antropología Social, de la misma universidad. Las líneas de investigación que desarrolla en la actualidad son: la antropología del cuerpo y el deporte, y la dimensión pedagógica del patrimonio y su relación con la ciudad.

Por último, tenemos el aporte de Nancy Solís, con su trabajo Organización para la vida: Relaciones recíprocas en las ventas ambulantes josefinas desde la perspectiva de la economía popular. La autora part del concepto de economía popular, para acercar al lector a la cotidianidad de los vendedores y vendedoras ambulantes de la ciudad de San José (Costa Rica), esbozando el ambiente de la venta ambulante y definiendo las estructuras organizadas alrededor de esta actividad. Nancy Solís es bachiller y Licenciada en Antropología Social de la Universidad de Costa Rica y actualmente labora en United World College Costa Rica.

Para finalizar esta introducción, desde Cuadernos de Antropología les invitamos a participar en la divulgación de sus investigaciones.

Bach. Benjamín Acevedo

Editor

Cuadernos de Antropología

http://revistas.ucr.ac.cr/index.php/antropologia 